\title{
A regional assessment of sources and fate of nitrate and methane in Alberta groundwater (Canada) using chemical and isotopic approaches
}

\author{
BERNHARD MAYER', PAULINE HUMEZ', LEAH WILSON', \\ MiCHAEL NightiNGALE', CYNTHIA MCCLAIN' \\ Department of Geoscience, University of Calgary, Calgary, \\ Alberta, Canada T2N 1N4 \\ (*correspondance: bmayer@ucalgary.ca)
}

Nitrate contamination in groundwater is a widespread problem in many countries with the potential for adverse health effects if the water is used for drinking water purposes. Methane is another groundwater consitutent that may have detrimental human health effects due to potential mobilization of trace metals in reducing groundwater, among others. The objectives of this study were to 1) conduct an assessment of the occurrence of nitrate and methane in groundwater throughout Alberta (Canada), a province with intensive agriculture and an extensive oil and gas industry; 2) to use isotope techniques to assess the predominant sources of nitrate and methane; and 3) to employ a combination of chemical and multi-isotopic techniques to assess the fate of nitrate and methane in groundwater.

Nitrate was detected in $34 \%(22,943$ of 66,421$)$ of groundwater samples collected from domestic wells with $\mathrm{NO}_{3}-\mathrm{N}$ concentrations ranging from $<0.1$ to $421 \mathrm{mg} / \mathrm{L}$. In $3.4 \%$ (2279 of 66,421 samples) of the groundwater samples the nitrate concentrations were above the maximum allowable concentration (MAC) in drinking water of $10 \mathrm{mg} / \mathrm{L} \mathrm{NO}_{3}-\mathrm{N}$. Stable isotope analyses revealed that elevated nitrate was predominantly derived from synthetic fertilizers and manure, and in a few cases from natural geogenic sources. Geochemical analyses revealed that $66 \%$ of all groundwater samples were moderately to highly reducing suggesting that denitrification is potentially a widespread $\mathrm{NO}_{3}$ removal process in groundwater in Alberta. Methane was frequently observed in groundwater samples throughout the province of Alberta with concentrations varying from $<1$ to $>30 \mathrm{mg} / \mathrm{L}$. Geochemical and isotopic parameters revealed that methane was biogenic often resulting from in-situ methanogenesis within the aquifers. For a subset of samples, upward migration of microbial methane into overlying aquifers followed by methane oxidation coupled with bacterial sulfate reduction and potentially denitrification was observed. These processes have the potential to lower the concentrations of groundwater contaminants such as methane and nitrate. 